\title{
La violence et la vérité ou les Provinciales à la Faculté des Lettres
}

\section{Dominique Descotes}

\section{(2) OpenEdition}

\section{Journals}

Édition électronique

URL : http://journals.openedition.org/ccibp/438

DOI : $10.4000 /$ ccibp. 438

ISSN : 2493-7460

Éditeur

Centre international Blaise Pascal

\section{Édition imprimée}

Date de publication : 5 avril 1985

Pagination : 19

ISSN : 0249-6674

\section{Référence électronique}

Dominique Descotes, «La violence et la vérité ou les Provinciales à la Faculté des Lettres », Courrier du

Centre international Blaise Pascal [En ligne], 7| 1985, mis en ligne le 27 novembre 2015, consulté le 02 mai 2019. URL : http://journals.openedition.org/ccibp/438 ; DOI : 10.4000/ccibp.438

Ce document a été généré automatiquement le 2 mai 2019.

Centre international Blaise Pascal 


\title{
La violence et la vérité ou les Provinciales à la Faculté des Lettres
}

\author{
Dominique Descotes
}

1 Le précédent Courrier du CIBP a rendu compte du récital Ordre par dialogues consacré aux Pensées et présenté, dans le grand amphithéâtre de la Faculté des Lettres de Clermont, par un groupe d'étudiants et de professeurs, aux participants des journées sur L'Accès aux «Pensées » de Pascal. L'appétit vient en mangeant : nous avons récidivé en 1986 avec deux représentations de La Violence et la Vérité consacrées aux Provinciales.

2 À dire vrai, l'équipe des récitants n'avait au départ qu'une connaissance assez restreinte des disputes touchant le pouvoir prochain et la grâce suffisante selon les Pères Le Moyne et Nicolaï et la doctrine des casuistes sur la probabilité ; on doutait un peu de la possibilité de faire rire le public sur de telles questions ou de l'intéresser à ces vieilles lunes. Quoique un peu laborieuses au début, les répétitions ont rapidement trouvé un rythme de croisière, à mesure que les interprètes se sont imprégnés de la rhétorique pascalienne. Ce fut pour eux une rencontre et une surprise, de même nature que celle des lecteurs des Petites Lettres en 1656, lorsqu'ils s'aperçurent qu'on pouvait parler de théologie en un style accessible à tous, sur le mode de la raillerie fine, du comique, avec par endroits une authentique fantaisie verbale. Pour ma part cette seconde expérience m'a confirmé dans la conviction que la récitation des textes demeure l'un des moyens les plus efficaces qui soient de faire connaitre, comprendre et aimer Pascal, y compris par ceux qui ne partagent ni ses certitudes ni ses engagements (et sur les Provinciales comme sur les Pensées, les réactions ont souvent été vives...). L'assimilation du fond des débats s'opère naturellement, sans difficulté, à mesure que les interprètes épousent les mouvements d'ironie ou la chaleur polémique, apprennent à attaquer l'adversaire de front ou à lui lancer avec précision la flèche du Parthe.

3 Faute de moyens, il était impossible de réaliser une mise en scène complexe : la sobriété s'est imposée de force. Au surplus, le montage du récital présentait des difficultés très différentes des Pensées : il ne s'agissait plus d'interpréter un enchaînement de fragments, il fallait jouer une action, incarner des personnages nettement individualisés, présenter dans leur continuité d'ensemble les discussions entre «Montalte » et les «théologiens » 
qu'il consulte et les discours chrétiens que Pascal adresse en son nom propre aux Jésuites dans les dernières lettres. En revanche, de la comédie initiale à l'éloquence sacrée, puis à l'angoisse de la persécution exprimée dans certains fragments préparatoires, l'itinéraire dramatique et la respiration du récital nous étaient donnés. Pour trouver le relief nécessaire, il fallait aussi donner la parole aux Jésuites: aussi avons-nous placé en arrière-scène un chœur de bons Pères, qui tantôt soutenaient leur confrère chargé d'exposer leur doctrine, tantôt lançaient des passages des Réponses du P. Nouët, S. J. aux Provinciales, tantôt répondaient à Pascal avec cette violence que condamne la XII ${ }^{\mathrm{e}}$ Lettre. Le rythme de l'ensemble confirmait l'éloge célèbre des qualités dramatiques des Provinciales formulé par Racine.

Les deux représentations n'ont pas déplu. Le compte-rendu d'un hebdomadaire clermontois nous a montré que le public a été sensible à la jeunesse et à l'actualisation du texte. On m'a aussi rapporté que sortant de l'amphithéâtre, un étudiant, dont je crois me rappeler que les Provinciales figuraient à son programmes de lectures, avait déclaré qu'après ce spectacle, il allait les lire... Mission accomplie... L'enregistrement de La Violence et la Vérité sur mini-cassette est disponible au CIBP. Voir plus loin.

Photographie de la repésentation de La Violence et la Vérité

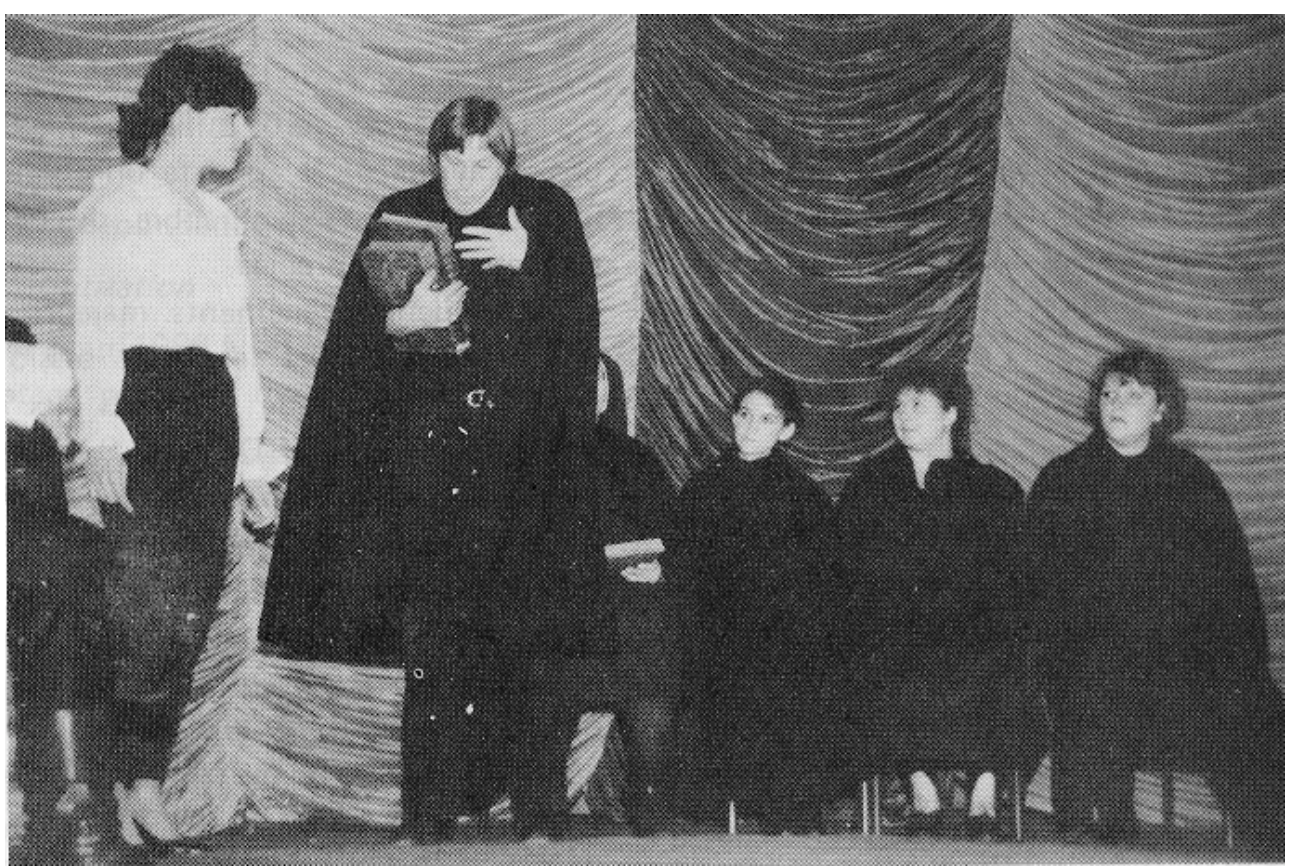

Cliché de Michel Quereuil

\section{INDEX}

Mots-clés : Provinciales 
AUTEUR

DOMINIQUE DESCOTES

CERHAC, Université Blaise Pascal 